\title{
Computational Design of Metal Ion Sequestering Agents
}

(Project Number: 54679)

\section{Principal Investigator}

Benjamin P. Hay

Pacific Northwest National Laboratory

P.O. Box 999

Richland, WA 99352

(509) 372-6239 (phone)

(509) 375-6631 (fax)

ben.hay@pnl.gov

\section{Co-Investigators}

David A. Dixon

Pacific Northwest National Laboratory

P.O. Box 999

Richland, WA 99352

(509) 372-4999 (phone)

(509) 375-6631 (fax)

david.dixon@pnl.gov

\section{Collaborators}

Robert T. Paine

Department of Chemistry

University of New Mexico

Albuquerque, NM 87131

(505) 277-1661 (phone)

(505) 277-2609 (fax)

rtpaine@unm.edu

Bruce A. Moyer

Oak Ridge National Laboratory

Oak Ridge, TN 37831

(423) 574-6718 (phone)

(423) 574-4939 (fax)

moyerba@ornl.gov
Brian M. Rapko

Pacific Northwest National Laboratory

P.O. Box 999

Richland, WA 99352

(509) 376-1571 (phone)

(509) 372-3861 (fax)

brian.rapko@pnl.gov

Kenneth N. Raymond

Department of Chemistry

University of California, Berkeley

Berkeley, CA 94720

(510) 642-7219 (phone)

(510) 486-5283 (fax)

raymond@garnet.berkeley.edu

Gilbert M. Brown

Oak Ridge National Laboratory

Oak Ridge, TN 37831

(423) 576-2756 (phone)

(423) 574-4939 (fax)

browngm1@ornl.gov 


\section{Research Objective}

Organic ligands that exhibit a high degree of metal ion recognition are essential precursors for developing separation processes and sensors for metal ions. Since the beginning of the nuclear era, much research has focused on discovering ligands that target specific radionuclides.

Members of the Group 1A and 2A cations (e.g., Cs, Sr, Ra) and the f-block metals (actinides and lanthanides) are of primary concern to DOE. Although there has been some success in identifying ligand architectures that exhibit a degree of metal ion recognition, the ability to control binding affinity and selectivity remains a significant challenge. The traditional approach for discovering such ligands has involved lengthy programs of organic synthesis and testing that, in the absence of reliable methods for screening compounds before synthesis, have resulted in much wasted research effort.

This project seeks to enhance and strengthen the traditional approach through computer-aided design of new and improved host molecules. Accurate electronic structure calculations are coupled with experimental data to provide fundamental information about ligand structure and the nature of metal-donor group interactions (design criteria). This fundamental information then is used in a molecular mechanics model (MM3) that helps us rapidly screen proposed ligand architectures and select the best members from a set of potential candidates. By using combinatorial methods, molecule building software has been developed that generates large numbers of candidate architectures for a given set of donor groups. The specific objectives of this project are

- to further understand the structural and energetic aspects of individual donor group-metal ion interactions and incorporate this information within the framework of MM3

- to further develop and evaluate approaches for correlating ligand structure with reactivity toward metal ions, in other words, screening capability

- to use molecule structure building software to generate large numbers of candidate ligand architectures for given sets of donor groups

- to screen candidates and identify ligand architectures that will exhibit enhanced metal ion recognition.

These new capabilities are being applied to ligand systems identified under other DOEsponsored projects where studies have suggested that modifying existing architectures will lead to dramatic enhancements in metal ion binding affinity and selectivity. With this in mind, we are collaborating with Professors R. T. Paine (University of New Mexico) and K. N. Raymond (University of California, Berkeley) and Drs. B. A. Moyer and G. M. Brown (Oak Ridge National Laboratory) to obtain experimental validation of the predicted new ligand structures. 
Successful completion of this study will yield molecular-level insight into the role that ligand architecture plays in controlling metal ion complexation and will provide a computational approach to ligand design.

\section{Research Progress and Implications}

This project is a renewal of the project "Architectural Design Criteria for f-Block Metal Sequestering Agents" that began in September 1996 and ended in May 2000. The original project, which combined theoretical and experimental approaches to investigate the interactions of amide ligands with metal ions, resulted in 28 presentations at meetings, workshops, and conferences, and 14 journal articles. Since then, there have been an additional six publications, with at least one more manuscript in preparation (vide infra), and four presentations. In addition, the PI is scheduled to present a seminar at Oak Ridge National Laboratory in June 2001 and has submitted abstracts for presentations at two conferences scheduled in August 2001. The followon research has led to the computational design of an improved architecture for a diamide sequestering agent for solvent extraction of lanthanides and actinides. Professor J. E. Hutchison (University of Oregon) has continued non-funded studies on this material. The new diamide has been prepared, and initial tests under solvent extraction conditions reveal a 4 order of magnitude increase in the europium distribution constant over that obtained with N,N,N',N'-

tetrahexylmalonamide. This finding suggests that application of our design criteria was successful.

Funding for this project was renewed on October 2000, and this report summarizes progress after 7 months of a 3-year period. The renewed scope is limited to theoretical research with an emphasis on both the development and application of computational methods for ligand design. One goal is to expand design capability to ligands bearing other types of donor groups including amines, carboxylates, and aminocarboxylates. To assist in this research, postdoctoral associate Tom Klinckman, recently graduated from Professor Tom Cundari's group at the University of Memphis, was recruited in October 2000 and arrived at Pacific Northwest National Laboratory in January 2001. Investigations of the structural and energetic aspects of these ligands and their metal complexes with lanthanides and actinides are now underway. These investigations include electronic structure calculations on structural components of polydentate aminocarboxylates, such as N,N,N',N'-tetramethyl-ethylenediamine and N,N-dimethylglycine; electronic structure calculations on metal complexes with unidentate donor groups, such as acetate and trimethylamine; and a statistical analysis of $\mathrm{x}$-ray structural data retrieved from the Cambridge Structural Database.

\section{Planned Activities}

- Develop an extended molecular mechanic model for amines, carboxylates, and aminocarboxylates and their f-block metal ion complexes.

- Demonstrate a capability to screen aminocarboxylate architectures for metal complex stability through correlation of structure-stability data available in the literature. 
- Couple molecular mechanics screening capability with structure building software.

- Apply computational tools to identify improved host architectures in collaboration with experimental research groups. The principal investigator plans on-site visits with experimental collaborators. The first visit is scheduled for June 2001 at Oak Ridge National Laboratory.

\section{Information Access}

\section{Publications Since May 2000}

Hay BP and RD Hancock. 2001. "The role of donor group orientation as a factor in metal ion recognition by ligands." Coord. Chem. Rev. 212:61-78.

Hay BP, BM Rapko, DA Dixon, R Vargas, J Garza, RD Rogers, and GA Broker. "Structural criteria for the rational design of selective ligands. 4 . Metal ion complexation by diamide chelate rings." manuscript in preparation.

Lumetta GJ, BK McNamara, BM Rapko, RL Sell, RD Rogers, GA Broker, and JE Hutchison. 2000. "Synthesis and characterization of mono- and bis-(tetraalkyl-malonamide)uranium(VI) complexes." Inorganica Chimica Acta 309:103-108.

Rao L, P Zanonato, P Di Bernardo, and A Bismondo. 2000. "Calorimetric and spectroscopic studies of $\mathrm{Eu}(\mathrm{III})$ complexation with tetramethylmalonamide and tetramethylsuccinamide in acetonitrile and dimethylsulfoxide." Inorg. Chim. Acta 306:49-64.

Rapko BM, BK McNamara, GJ Lumetta, RD Rogers, GA Broker, and BP Hay. 2000. "Coordination of lanthanide ions containing non-coordinating counteranions with $\mathrm{N}, \mathrm{N}, \mathrm{N}$ ', N'tetramethylsuccinamide (TMSA). I. Preparation and characterization of [(TMSA) $\mathrm{Ln}][\mathrm{A}]_{3}, \mathrm{~A}=$ $\mathrm{ClO}_{4}{ }^{-}, \mathrm{CF}_{3} \mathrm{SO}_{3}{ }^{-}$." Inorg. Chem. 39:4858-4867.

Vargas R, J Garza, DA Dixon, and BP Hay. 2000. "Conformational analysis of N,N,N',N'tetramethylsuccinamide: Importance of C-H $\cdots$ O hydrogen bonds?" J. Phys. Chem. A 104:51155121.

Vargas R, J Garza, DA Dixon, and BP Hay. 2000. "How Strong is the C(alpha)-H $\bullet \cdot \mathrm{O}=\mathrm{C}$ Hydrogen Bond?" J. Am. Chem. Soc. 122:4750-4755 and highlighted in C\&E News, 2000, Volume 78, Page 15 News of the Week article "Protein Folding. Weak Hydrogen Bonds in Peptide Backbones May Play Significant Role." 


\section{Presentations Since May 2000}

BP Hay, DA Dixon, and BM Rapko. 2001. "Computational design of metal ion sequestering agents." Abstract submitted to the EMSP Symposium, 222 ${ }^{\text {nd }}$ American Chemical Society National Meeting to be held in Chicago, Illinois.

Gilbertson RD, BM Rapko, BP Hay, JE Hutchison, and TJR Weakly. 2001. "Synthesis of a conformationally constrained malonamide and its coordination chemistry with uranyl nitrate." $221^{\text {st }}$ American Chemical Society National Meeting, San Diego, California.

Hay BP, DA Dixon, and BM Rapko. 2001. "Computational design of metal ion sequestering agents (EMSP 54679).” Tanks Focus Area (TFA) FY 2001 Midyear Review, Salt Lake City, Utah.

Hay BP. 2000. "Building a better mousetrap: ligand design with molecular mechanics." American Chemical Society, Pacifichem 2000 Meeting in Honolulu, Hawaii.

Hay BP. 2001. "HostBuilder: A combinatorial structure generator for host discovery." Separations Group Seminar to be held at Oak Ridge National Laboratory, Oak Ridge, Tennessee.

Klinckman TR, DA Dixon, and BP Hay. 2001. "An MM3 force field for metal complexes with amines, carboxylates, and aminocarboxylates." Abstract submitted to the Inorganic Poster Session, $222^{\text {nd }}$ American Chemical Society National Meeting to be held in Chicago, Illinois.

Lumetta GJ, BK McNamarra, BM Rapko, RD Rogers, GA Broker, and JE Hutchison. 2001. "Extraction of U(VI) with malonamides: what's really going on?" $221^{\text {st }}$ American Chemical Society National Meeting, San Diego, California. 